\title{
HYDROGEN AS AN ALTERNATIVE FUEL FOR COMMERCIAL
}

\author{
AIRPLANES \\ Nithyapathi.C ${ }^{\mathbf{1}}$, Aravind Kumar T.R ${ }^{\mathbf{2}}$, Subanesh Shyam $\mathbf{R}^{\mathbf{3}}$ \\ ${ }^{1}$ Faculty Aeronautical Engineering (PG), ${ }^{2,3}$ Aeronautical Engineering (UG), Karpagam University, Pollachi Main Road, \\ Coimbatore, \\ 1'shribathi2024@gmail.com, ${ }^{2}$ hp7540arunkumar@gmail.com, ${ }^{3}$ subanesh001shyam@gmail.com
}

\begin{abstract}
Air traffic today contributes about $3 \%$ to the anthropogenic greenhouse effect. This number may change due to increase of air traffic and the decrease of the major $\mathrm{CO}_{2}$ producers of the day. $\mathrm{LH}_{2}$ could be an alternative to the hydrocarbon fuel like cheap kerosene or any other designed hydrocarbon fuel. It could be fuel suitable for aircraft to be produced from renewable energy and offering extremely low emissions (zero $\mathrm{CO}_{2}$, very low $\mathrm{NO}_{X}$ ). It has the potential to eliminate the dependency of aviation upon dwindling crude oil resources and to reduce dramatically, the contribution of aviation to the anthropogenic greenhouse effect. Use of liquid hydrogen hence could allow sustainable growth of aviation at high rates(typically 4-5\% per year) with an extreme low impact on the environment.
\end{abstract}

Keywords: hydrogen, environment, aviation.

\section{INTRODUCTION}

Petroleum products have always been the preferred transportation fuels because they offer the best combination of energy content, performance, availability, ease of handling and price. However, the recent increase in the price of oil has prompted the industry to look at alternatives. Besides price, other factors must be taken into account when considering alternative fuels. Of course, safe and reliable operation of the engine and aircraft must not be compromised in anyway.

Alternative fuels for aviation have been considered since the early days of turbine engines. By using liquid-hydrogen, there is a potential to create aircraft that are capable of the same missions as current aircraft, but use less energy, use less natural resources, have smaller environmental impact, and are as safe as or safer than current aircraft. Natural occurring hydrocarbon fuels will rise in demand and cost as developing countries require more energy, while at the same time oil reserve diminish. There are several alternative fuels to hydrogen, however hydrogen is the only fuel which avoids all emissions except water vapor and nitrous oxide.

\section{A. Aviation Fuel}

Aviation fuel is specialized type of petroleum-based fuel used to power aircraft. It is generally of a higher quality than used in less critical applications such as heating or road transport, and often contains additives to reduce the risk of icing or explosion due to high temperatures, amongst other properties. The general aviation fuels in use are Jet A/Jet A-1, Kerosene, FT Synthetic Fuel, Methane, Gasoline and Bio-fuel.

\section{B. Alternative Aviation Fuel}

Fuels derived from feed stocks such as coal, natural gas, biooils and cellulose matter were widely used during WW-II. The most pervasive method of conversion includes reforming the feed stocks trough heat and catalytic reactions to syngas $(\mathrm{CO}$ and $\mathrm{H} 2$ ) followed by conversion of the syngas into synthetic crude via the Fischer-Tropsch (FT) process. The synthetic crude is further hydro fractured to synthesize paraffin with a small percentage of non-paraffin.

Plant derived fuels include feed stocks derived from soya bean oils, palm oils, corn, switch grass and algae. These resources are considered renewable, but most would require large areas of plant nurturing. As such, bio-derived fuels offer a reduction in life cycle $\mathrm{CO} 2$ and many can be very attractive fuel candidates. The potential alternative fuels are discussed in detail below:

1) Jet Fuel: Jet fuel is a type of aviation fuel designed for use in aircraft powered by gas-turbine engines. It is cleared to straw-colored in appearance. The most commonly used fuels for commercial aviation are Jet $\mathrm{A}$ and Jet A-1 which are produced to a standardized international specification. The only other jet fuel commonly used in civilian turbine-engine powered aviation is Jet B which is used for its enhanced coldweather performance. Jet fuel is a mixture of large number of different hydrocarbons. The range of their sizes is restricted by the requirements for the product, for example: freezing point or smoke point. Kerosene type jet fuel has a carbon number distribution between about 8 and 16 carbon numbers; wide-cut 
or naphtha-type jet fuel between about 5 to 15 carbon numbers.

Turbine engines can operate with a wide range of fuels and jet aircraft engines typically use fuels with higher flash points, which are less flammable and therefore safer to transport and handle. The first jet fuels were based on kerosene or a gasoline-kerosene mix and most jet fuels are still kerosenebased.

2) Cryogenic Fuels: The term cryogenic fuel refers to materials that are gasses at normal ambient conditions that have been cooled to their boiling point and stored as low temperature liquids. Examples are liquid hydrogen and liquid methane. Both of these fuels have very high gravimetric energy content, but their low density leads to low volumetric energy content. Both fuels are fundamentally different from jet fuel and would require a new fuel infrastructure in addition to new engines and airframes.

\section{RELATED WORK}

A. Contreras, *, S. Yiğit†, K. Özay†, T.N. Veziroğlu†, (1997) has proposed hydrogen will be replacing fossil fuels is air transportation, an area that has been under research for several decades. Hydrogen as an energy carrier for use in airplanes has some unique attributes like global availability, safety, minimum pollution and light weight, making it an ideal fuel. C.-J. Winter, (1990) has proposed use of hydrogen in aviation, which is centered on plans for supersonic/hypersonic aircraft using hydrogen as a fuel. A more complex challenge includes achieving environmental compatibility for this technology, which is well possible in the areas of producing and handling hydrogen fuel. Another formidable precondition is achieving an international political consensus that a transition from the established global hydrocarbon energy economy to a potential global hydrogen energy economy, in which aviation could have a trail-blazer function, is necessary, achievable and urgent.

\section{PROPOSED WORK}

Performance of hydrogen combustion and effluent emissions can be compared with data's of other aviation fuels used at present. A 2-D combustion chamber model is designed in GAMBIT and then the analysis of various aviation fuel flows into the chamber is to be carried out well using FLUENT 6.3. The properties and behavior of $\mathrm{LH} 2$ are discussed in this paper as an alternative fuel in commercial operation and compare the performance of Hydrogen with all other aviation fuels.

\section{A. Physical Property}

1) Density: Density is measured as the amount of mass contained per unit volume. Density values only have meaning at a specified temperature and pressure since both of these parameters affect the compactness of the molecular arrangement, especially in a gas. The density of a gas is called its vapor density and the density of a liquid is called its liquid density.

Table 1 Density of comparative fuels

\begin{tabular}{|l|l|l|}
\hline \multicolumn{1}{|c|}{ Substance } & \multicolumn{1}{|c|}{$\begin{array}{c}\text { Vapor Density } \\
\left(\mathbf{a t ~}^{\mathbf{6}} \mathbf{F} ; \mathbf{2 0}^{\mathbf{0}} \mathbf{C}, \mathbf{1 a t m}\right)\end{array}$} & $\begin{array}{c}\text { Liquid Density } \\
\text { (at normal } \\
\text { boiling point) }\end{array}$ \\
\hline HYDROGEN & $0.005229 \mathrm{lb} / \mathrm{ft}^{3}$ & $4.432 \mathrm{lb} / \mathrm{ft}^{3}$ \\
& $\left(0.08376 \mathrm{Kg} / \mathrm{m}^{3}\right)$ & $\left(70.8 \mathrm{Kg} / \mathrm{m}^{3}\right)$ \\
\hline METHANE & $0.0406 \mathrm{lb} / \mathrm{ft}^{3}$ & $26.4 \mathrm{lb} / \mathrm{ft}^{3}$ \\
& $\left(0.65 \mathrm{Kg} / \mathrm{m}^{3}\right)$ & $\left(422.8 \mathrm{Kg} / \mathrm{m}^{3}\right)$ \\
\hline GASOLINE & $0.275 \mathrm{lb} / \mathrm{ft}^{3}$ & $43.7 \mathrm{lb} / \mathrm{ft}^{3}$ \\
& $\left(4.4 \mathrm{Kg} / \mathrm{m}^{3}\right)$ & $\left(700 \mathrm{Kg} / \mathrm{m}^{3}\right)$ \\
\hline
\end{tabular}

2) Expansion Ratio: The difference in volume between liquid and gaseous hydrogen can easily be appreciated by considering its expansion ratio. Expansion ratio is the ratio of the volume at which a gas or liquid is stored compared to the volume of the gas or liquid at atmospheric pressure and temperature. When hydrogen is stored as a liquid, it vaporizes upon expansion to atmospheric conditions with a corresponding increase in volume. Hydrogen's expansion ratio of 1:848 means that hydrogen in its gaseous state at atmospheric conditions occupies 848 times more volume that it does in its liquid state. When hydrogen is stored as a high pressure gas at 3600 psig(250 bar) and atmospheric temperature, its expansion ratio to atmospheric pressure is $1: 240$.

\section{B. Chemical Property}

1) Flammability: Three things are needed for a fire or an explosion to occur: fuel, oxygen and a source of ignition. Hydrogen, as a flammable fuel, mixes with oxygen whenever air is allowed to enter a hydrogen vessel, or when hydrogen leaks from any vessel into the air. Ignition sources take the form of sparks, flames or high heat.

2) Flash Point: All fuels burn only in a gaseous or vapor state. Fuels like hydrogen and methane are already gases at atmospheric conditions, whereas other fuels like gasoline or diesel that are liquids must convert to a vapor before they will burn. The characteristic that describes how easily these fuels can be converted to a vapor is the flashpoint. The flashpoint is defined as the temperature at which the fuel produces enough vapors to form an ignitable mixture with air at its surface.

If the temperature of the fuel is below its flashpoint, it cannot produce enough vapors to burn since its evaporation rate is too slow. Whenever a fuel is at or above its flashpoint, vapors are present. The flashpoint is not the temperature at which the fuel bursts into flames; that is the auto ignition temperature. 
3) Auto ignition Temperature: The auto ignition temperature is the minimum temperature required to initiate self-sustained combustion in a combustible fuel mixture in the absence of a source of ignition. In other words, the fuel is heated until it bursts into flame.

Each fuel has a unique ignition temperature. For hydrogen, the auto ignition temperature is relatively high at $1085 \mathrm{oF}$. This makes it difficult to ignite a hydrogen/air mixture on the basis of heat alone without some additional ignition source.

4) Octane Number: The octane number describes the antiknock properties of a fuel when used in an internal combustion engine. Knock is a secondary detonation that occurs after fuel ignition due to heat buildup in some other part of the combustion chamber. When the local temperature exceeds the ignition temperature, knock occurs.

The performance of the hydrocarbon octane is used as a standard to measure resistance to knock, and is assigned a relative octane rating of 100 . Fuels with an octane number over 100 have more resistance to auto-ignition than octane itself. Hydrogen has a very high research octane number and is therefore resistant to knock even when combusted under very lean conditions. The octane numbers of comparative fuels are indicated in table. The octane number has no specific relevance for use with fuel cells.

Table 2 Octane number of comparative fuels

\begin{tabular}{|l|l|}
\hline \multicolumn{1}{|c|}{ Fuel } & \multicolumn{1}{c|}{ Octane Number } \\
\hline HYDROGEN & $130+($ lean burn) \\
\hline METHANE & 125 \\
\hline PROPANE & 105 \\
\hline OCTANE & 100 \\
\hline GASOLINE & 87 \\
\hline DIESEL & 30 \\
\hline
\end{tabular}

\section{Geometry}

The model is created using GAMBIT pre-processor software. The working domain is generated with the help of the geometry. A combustor is created such that inlet and outlet faces are perpendicular to the flow. So the flow entering normal to the inlet face will automatically behave as the free stream air.

The geometry of the combustor is created using the vertices. The vertices are connected using the straight line creating the surface of the wall such that it forms to edges one will act as nozzle as a center wall. The geometry of the combustor in 2D is shown below in the fig.

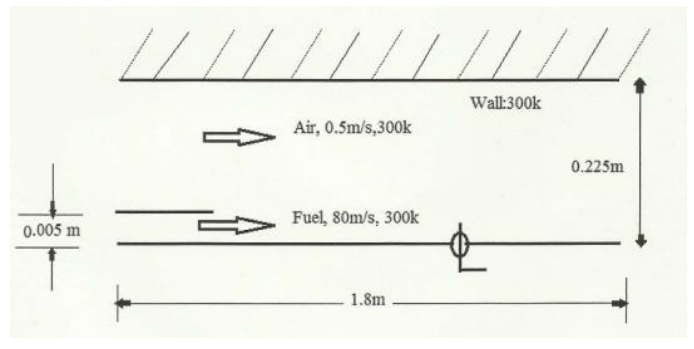

Fig 1 Geometry of Combustor

A combustor of length $1.8 \mathrm{~m}$ and height $0.225 \mathrm{~m}$ is created as 2D model. The high speed fuel jet initially expands with little interference from the outer wall and mixes with the low speed air, the Reynolds number based on the fuel jet diameter is approximately 28,000 .

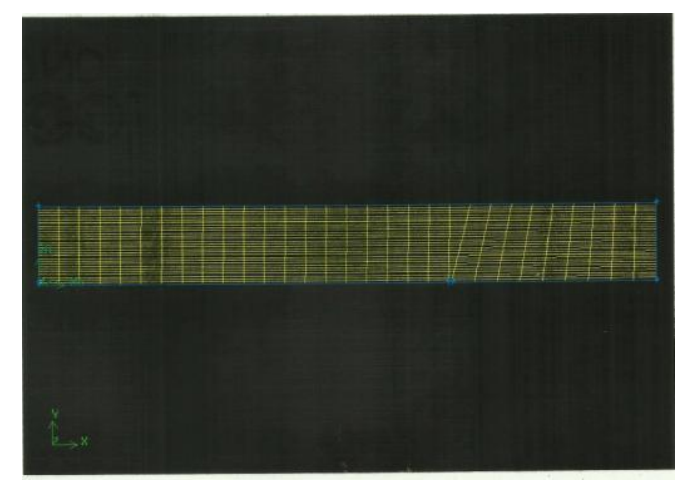

Fig 2 Domain

The meshing on the domain is done with structured mesh at both the faces. Clustering of mesh is done near the wall in order to capture the boundary layer clearly. Meshing of domain is created using Quadrilateral mesh. The domain consists of 930 nodes and 869 elements.

\section{Analysis}

The mesh is generated in GAMBIT and is solved using FLUENT. FLUENT is a commercial CFD code that solves the RANS model accurately. It uses a second order upwind discretization based on the simple pressure velocity coupling and the formulation can accommodate compressible flows. It solves equations describing the airflow of the model case by conservation of momentum, mass and energy.

\section{1) Boundary Condition}

Air-Fuel mixture is allowed to pass through the combustor 2D model, it is made possible through species transport and gaseous combustion. Air is passed inside the combustor at the velocity of $0.5 \mathrm{~m} / \mathrm{s}$ and fuel is passed at the rate of $80 \mathrm{~m} / \mathrm{s}$, whose wall is maintained at the temperature of $300 \mathrm{~K}$ initially and then increased to $2000 \mathrm{~K}$ later. Extra fuel can be sprayed through the opening provided at certain distance from the 
combustor end. From the species transport, aviation fuel mixture can be added to the analysis. Properties and the mixing rate of the reactions are provided.

Table 3 Domain Condition

\begin{tabular}{|l|l|}
\hline \multicolumn{1}{|c|}{ Edge Name } & \multicolumn{1}{c|}{ Boundary Type } \\
\hline Symmetry & Axis \\
\hline Wall 1 & Wall \\
\hline Outlet & Pressure Outlet \\
\hline Air Inlet & Velocity Inlet \\
\hline Fuel Inlet & Velocity Inlet \\
\hline
\end{tabular}

FLUENT offers various "under-relaxation factor" which reduces the change in variable iterations. The convergence of a solution is measured by the residuals or differences between the previous iteration and the current iteration. For all simulations the residuals were set to appropriate values. FLUENT continued iterating until the solution is converged and all residuals fell below the appropriate values.

\section{RESULT AND DISCUSSION}

\section{A. Comparison Chart}

1) Density: It is defined as the amount of mass contained per unit volume.

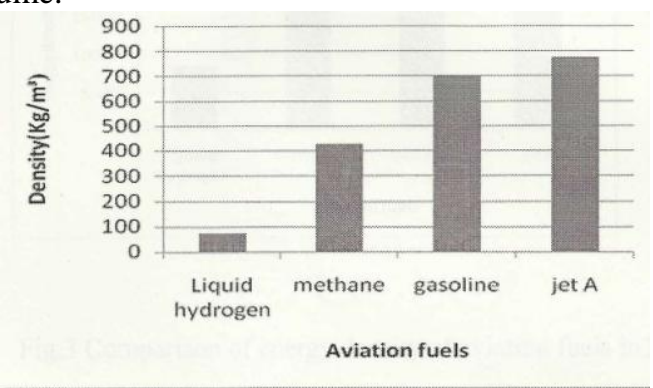

Fig 3 Comparison of density of aviation fuels in $\mathrm{Kg} / \mathrm{m} 3$

2) Auto Ignition Temperature: It is the minimum temperature required to initiate self-sustained combustion in a combustible fuel mixture in the absence of a source ignition.

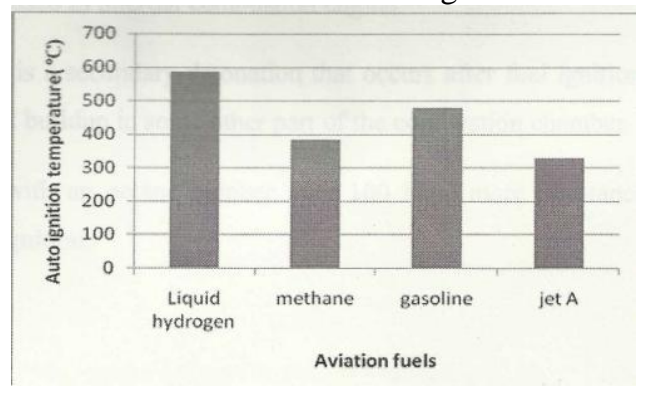

Fig 4 Comparison of auto ignition temperature of aviation fuels in $0 \mathrm{C}$
3) Flash Point: The temperature at which the fuel produces enough vapors to form an ignitable mixture with air as its surface.

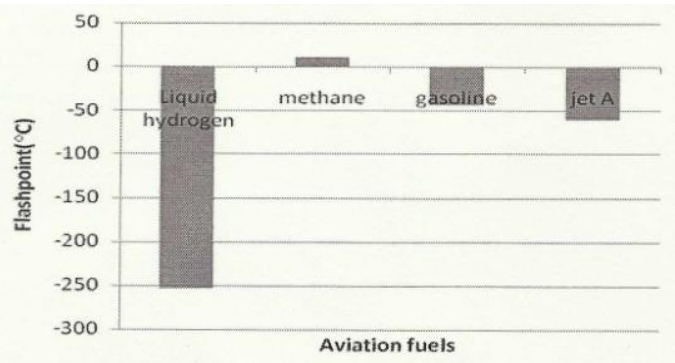

Fig 5 Comparison of flash point of aviation fuels in 0C

4) Octane Number: It describes the anti-knock properties of a fuel when used in internal combustion engine.

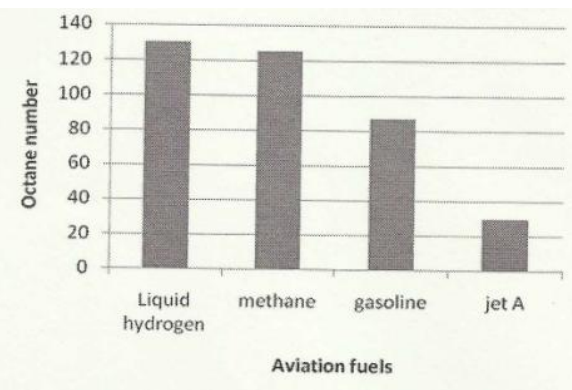

Fig 6 Comparison of Octane number of aviation fuels

5) Freezing Point: The temperature below which a liquid turns into a solid.

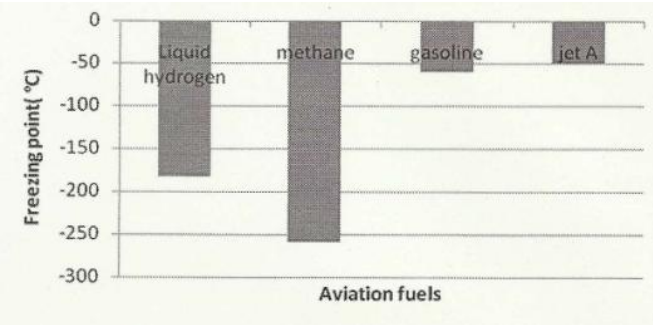

Fig 7 Comparison of Freezing Point of aviation fuels

6) $\mathrm{CO} 2$ Emission: Aviation fuel with more carbon atoms emits more $\mathrm{CO} 2$ as pollutant. 


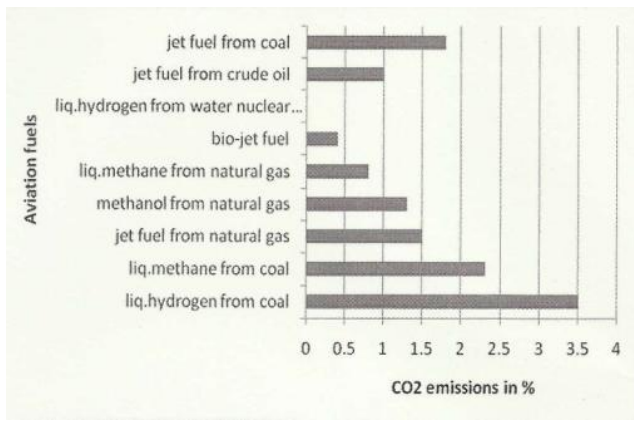

Fig 8 Comparative chart of $\mathrm{CO} 2$ emission by various aviation fuels

\section{B. Analyzed Hydrogen Data's}

1) Static temperature

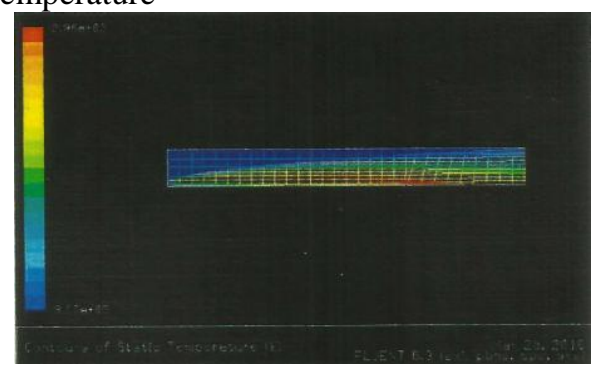

Fig 9 Contour of Static Temperature of Hydrogen-Air

2) Mass Fraction of pollutant NOX

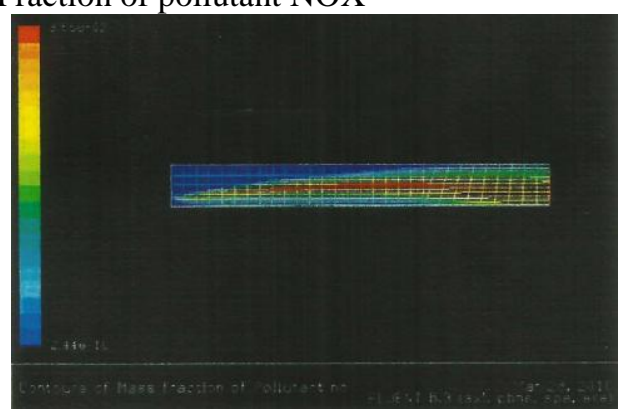

Fig 10 Contour of pollutant NOX of Hydrogen-Air

\section{3) NOX Emission}

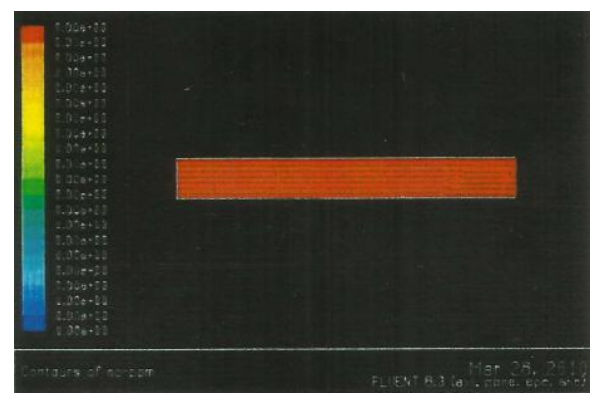

Fig 11 Contour of pollutant NOX of Hydrogen-Air
4) Velocity Vs Static temperature

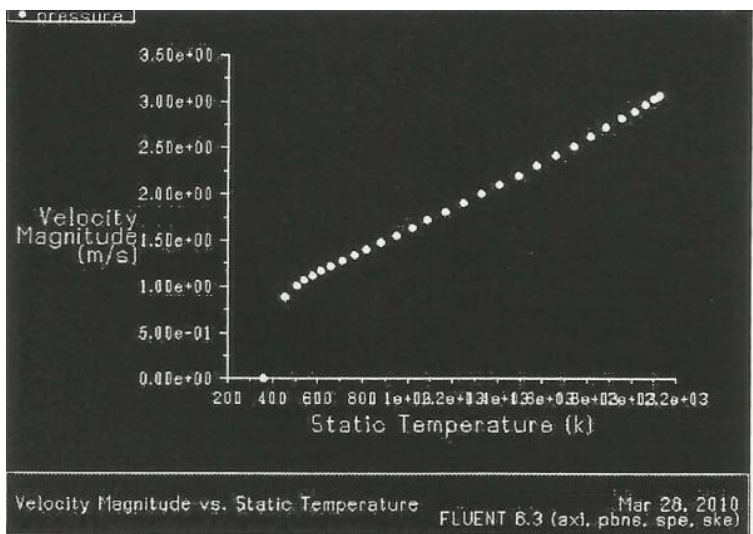

Fig 12 Graph of Velocity Vs Static Temperature

\section{CONCLUSIONS}

From the computational analysis the performance of Hydrogen-Air is far better than other fuels, while considering the side of pollutants. From the results, it is very clear that hydrogen is the only fuel that emits zero NOX.

The result predicted using the FLUENT code satisfies the theoretical computations of hydrogen properties.

Hence, it can be concluded from the combustion study that,

1. Emission of harmful $\mathrm{NO}_{\mathrm{X}}$ is zero.

2. Emission of $\mathrm{CO}_{2}$ is also zero as it does not have carbon atoms unlike other aviation fuels.

3. Specific heat is less such that less amount of heat per unit mass is enough to raise the temperature.

4. Also from the comparison chart, hydrogen has the appreciable property values.

\section{REFERENCES}

[1] A. Contreras, *, S. Yiğit†, K. Özay†, T.N. Veziroğlu†(1997) 'Hydrogen as aviation fuel: A comparison with hydrocarbon fuels' International Journal of Hydrogen Energy Volume 22, Issues 10-11, October-November 1997, Pages 1053-1060.

[2] C.-J. Winter (1990) ' Hydrogen in high-speed air transportation' International Journal of Hydrogen Energy Volume 15, Issue 8, 1990, Pages 579-595.

[3] Maxwell Smith (1970) 'Aviation Fuels' G.T.Foulis \& Co Ltd, page.414.

[4]. Ottino J.M (2001) 'Hydrogen Property' Rev.0, December. 